\title{
Peutz-Jeghers syndrome with metastasizing duodenal carcinoma
}

\author{
J. P. WILLIAMS AND ANTHONY KNUDSEN
}

From the West Middlesex Hospital, Isleworth

EDITORIAL SYNOPSIS Since interest was first aroused in the Peutz-Jeghers syndrome there have been conflicting views as to the frequency with which malignant change occurs in the polyps found in the small intestine, and this has been due to the difficulty of interpreting the histological structure of the polypi. Many now feel that in this syndrome these lesions are hamartomas and that the apparent early malignant change is due to epithelial elements being caught up in the interlacing bands of smooth muscle.

The case recorded here may well be the first fully documented example of carcinomatous change in a polyp in the Peutz-Jeghers syndrome, a metastasis having occurred in a regional lymph gland and the patient dying 15 months after the operation.

Since the descriptions of Peutz (1921) and Jeghers, McKusick, and Katz (1949) the syndrome of mucocutaneous pigmentation and intestinal polyposis has become well recognized. The familial character of the condition and the tendency to intussusception is now established but considerable confusion remains regarding the malignant potentiality of the intestinal polyps. Many writers have considered the syndrome to be precancerous and thus similar in behaviour to the unrelated condition of familial polyposis coli. Some 20 cases of alleged malignancy in the PeutzJeghers syndrome are now recorded but it is significant that there is no previous report of an adequately studied case in which metastasis of a small bowel cancer has occurred. Furthermore, follow-up studies of these patients have failed to confirm the gloomy prognosis usually associated with such tumours. It is now apparent that an erroneous histological diagnosis of malignancy may readily be made in this condition through misinterpretation of the unusual appearances of the intestinal polyps. It is becoming recognized that, contrary to earlier belief, the Peutz-Jeghers syndrome carries little risk of malignancy. While we entirely agree with this view the following case is reported as it shows the exceptional occurrence of true malignant change in a Peutz-Jeghers polyp of the duodenum with metastasis and subsequent death of the patient.

CASE REPORT

A married white woman aged 52 was admitted to the West Middlesex Hospital on 27 January 1960 under the care of Mr. J. Scholefield. Two months previously she had had an attack of pain in the left iliac fossa associated with vomiting. One week before admission the pain had recurred with vomiting and diarrhoea and these symptoms had persisted and increased in severity. The patient had noticed blood in the stool on one occasion during this last episode.

A hysterectomy for fibroids had been performed in 1944 , otherwise her life had been medically without incident. She had never been pregnant. There was no family history of pigmentation, abdominal pain, or rectal bleeding.

On examination the patient was pale and in pain but was not shocked. The buccal mucosa, arms, and hands were pigmented (Figs. 1 and 2). The cardiovascular and respiratory systems were normal. The blood pressure was $145 / 85 \mathrm{~mm}$. Hg. The tongue was clean and moist. The abdomen was not distended and there was no visible peristalsis. Gut sounds were increased but of normal quality. A sausage-shaped mass was palpable in the left iliac fossa. The rectum was ballooned and a mass was palpable outside the rectal wall on the left side.

After the patient's admission the symptoms and signs resolved rapidly without any treatment, so much so indeed that it was considered reasonable to perform a barium trace of the small intestine. This was carried out by Dr. M. J. Wright. The duodenum appeared a little dilated and there was a large amount of fluid in the stomach. Examination at four hours showed almost complete obstruction in the last part of the duodenum with enormous dilatation of the duodenal loop.

The haemoglobin was $9.2 \mathrm{~g} . / 100 \mathrm{ml}$. (62\%), blood group A Rhesus positive. In view of the anaemia a pre-operative transfusion of 3 pints of blood was given.

LAPAROTOMY On 3 February an upper right paramedian incision was made and subsequently extended to full 


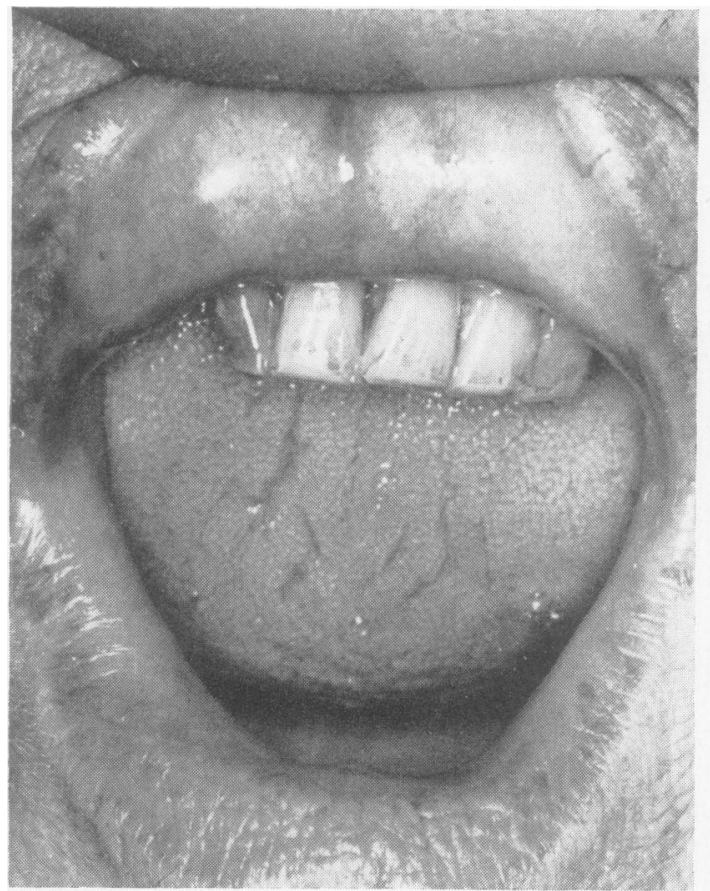

FIG. 1.

FIGS. 1 and 2. Pigmentation of arms, hands, and buccal mисоsa.

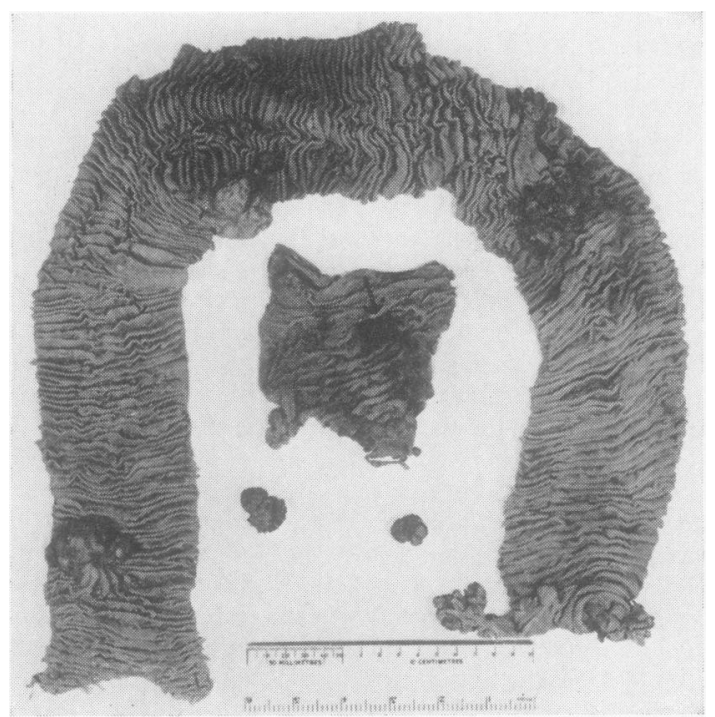

FIG. 3 .

FIG. 3. Resected segments of jejunum and duodenum. The arrow indicates the site of the duodenal carcinoma.

FIG. 4. The appearance of the jejunum showing a major pedunculated polyp and multiple small sessile polyps.

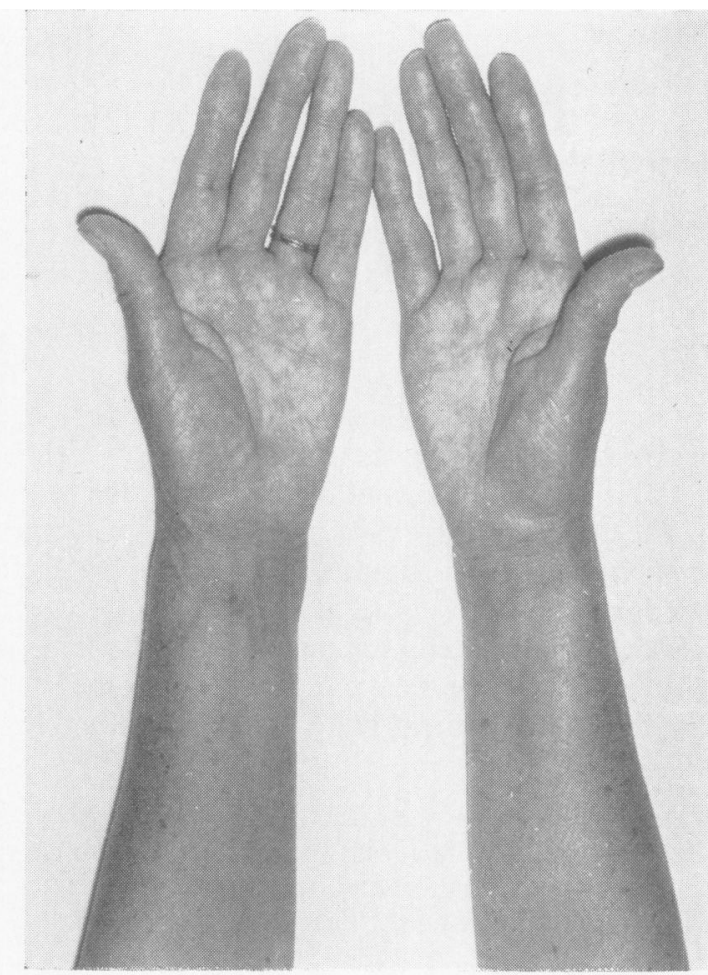

FIG. 2 .

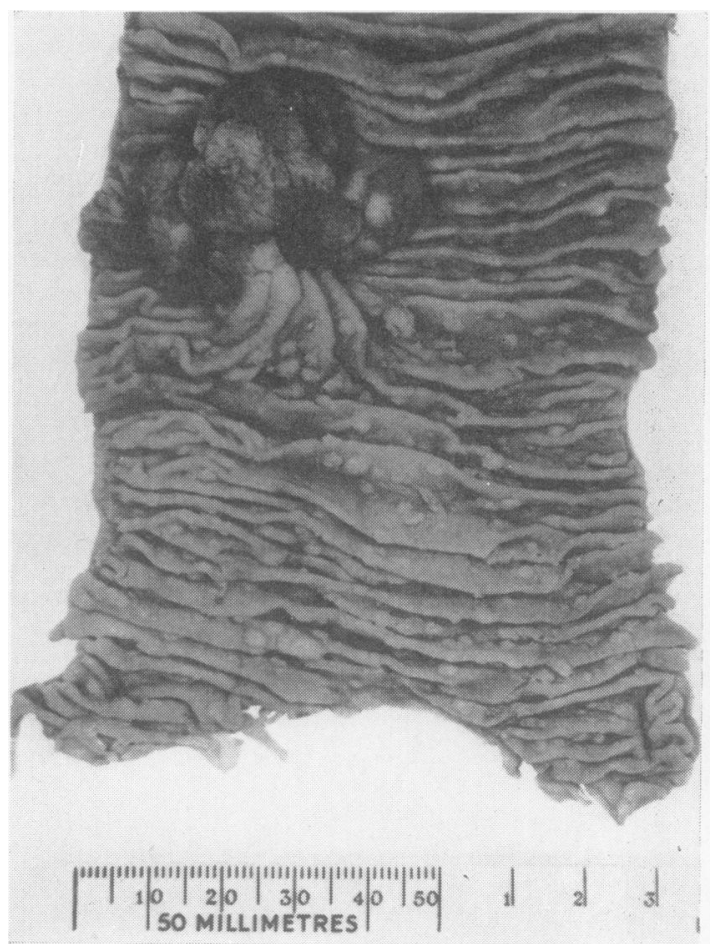

FIG. 4. 


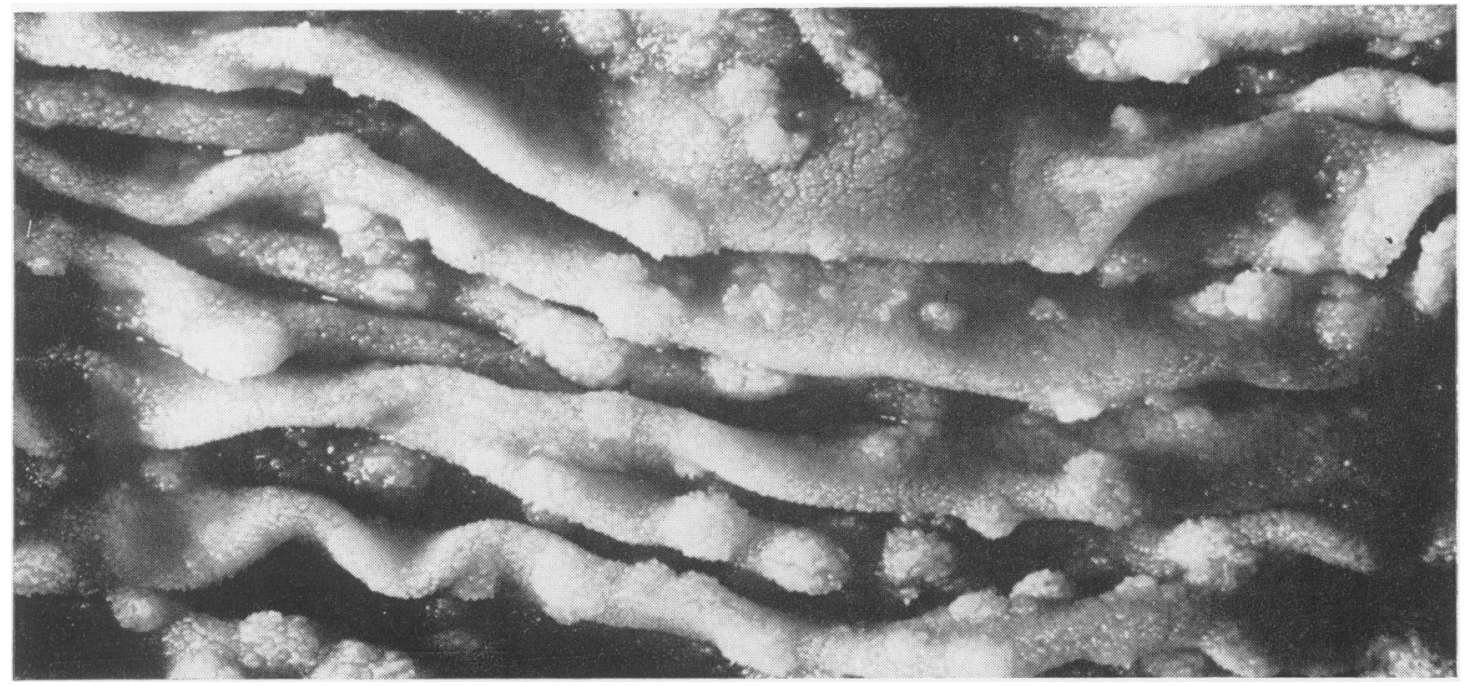

FIG. 5. Close-up view of the jejunal mucosa.

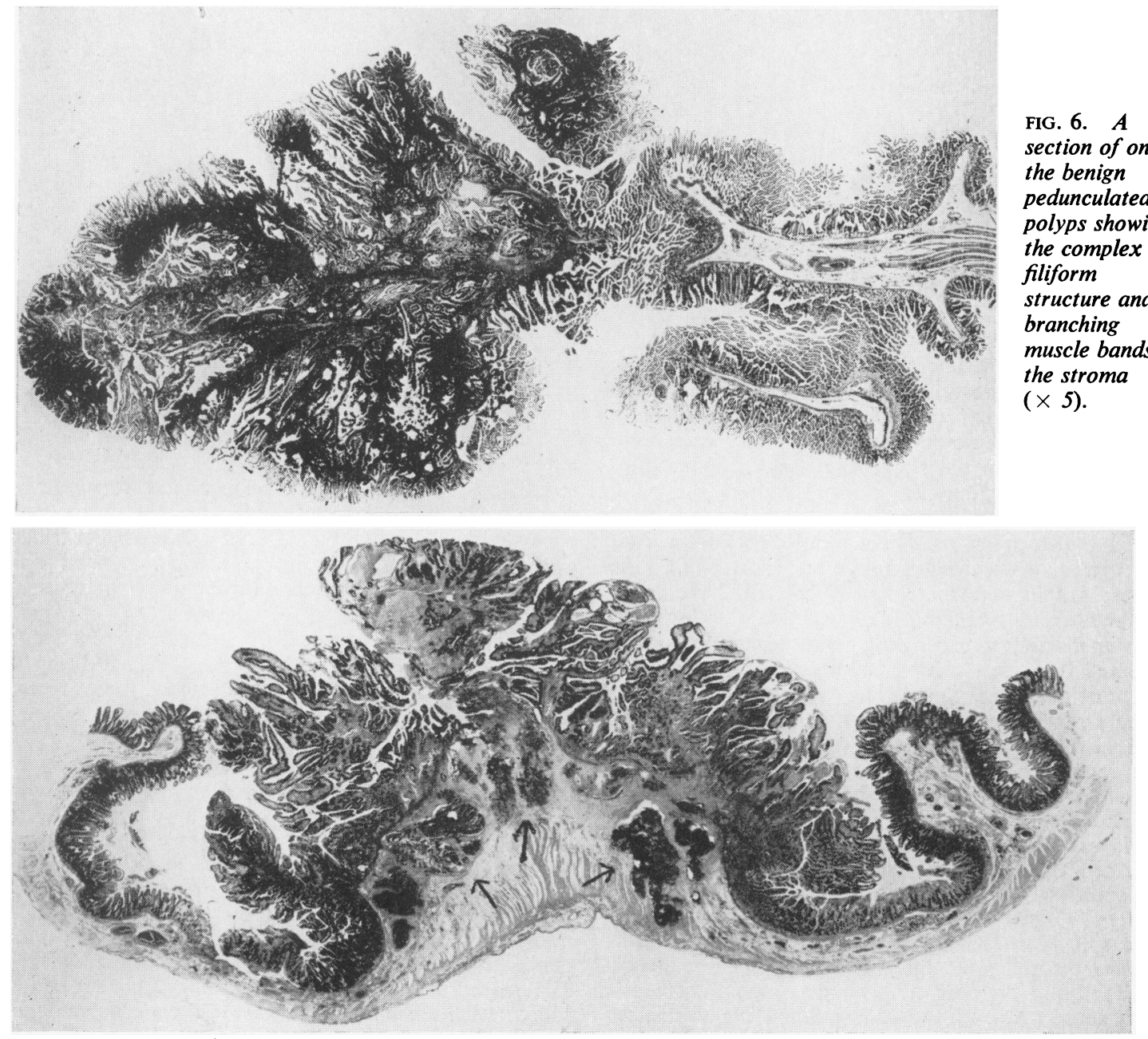

FIG. 7. A section of the malignant polyp in the duodenum. Invasion of the base by mucoid adenocarcinoma is indicated by the arrows $(\times 10)$. 


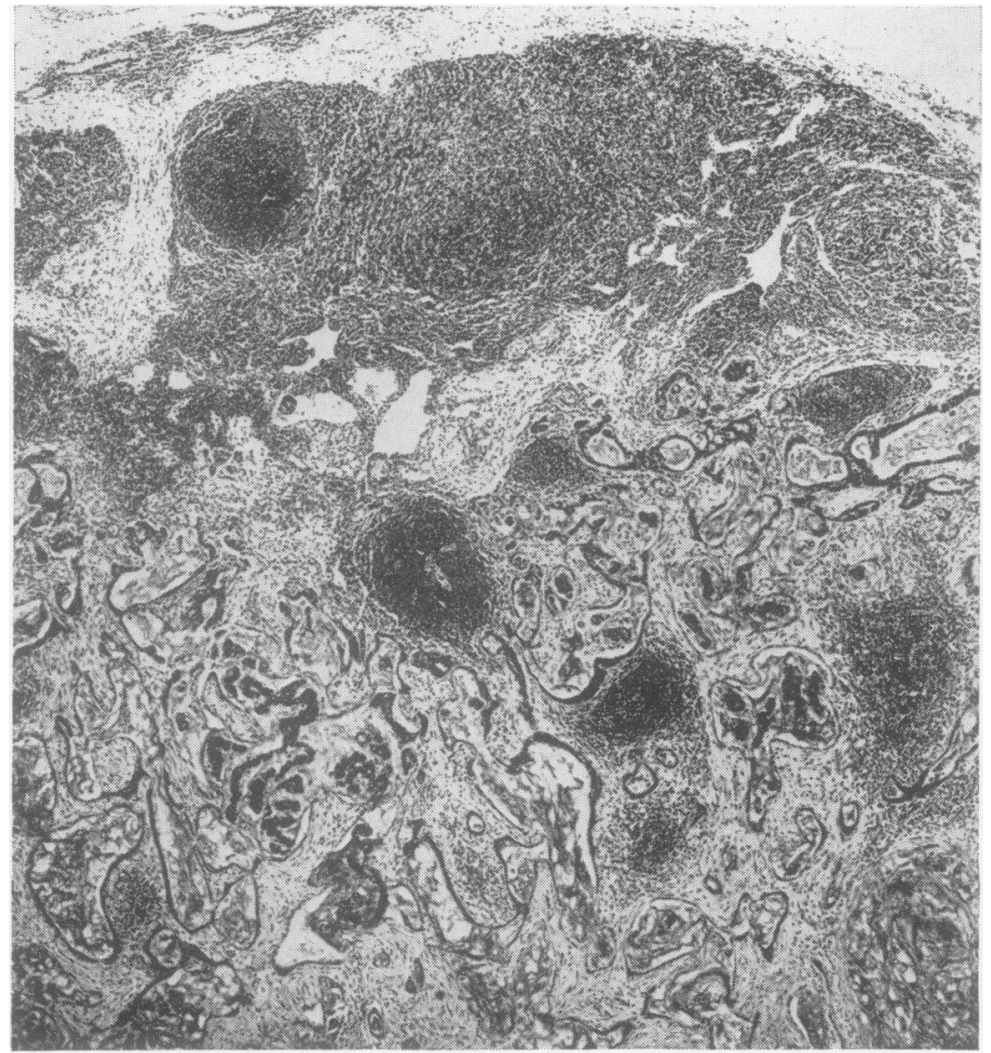

FIG. 8. Invasion of a lymph node $(\times 30)$.

length (J.P.W.). Numerous adhesions between the ileum and the previous hysterectomy incision were divided. The stomach was collapsed and the duodenum dilated to twice the normal size. Polypoidal masses were palpable within the third and fourth parts of the duodenum and throughout the whole length of the small intestine. In the upper jejunum one of these polyps had formed the apex of an intussusception. A number of hard, apparently malignant, lymph nodes surrounded the origin of the superior mesenteric artery. The large bowel and the liver appeared and felt normal.

An apical mesenteric lymph node was removed and examined by frozen section, when invasion by mucoid adenocarcinoma was found. The duodenum was divided at the junction of its second and third parts and the terminal duodenum and proximal two feet of jejunum were resected. Attempt at removal of the remaining nodes in continuity proved extremely hazardous and was abandoned. Anastomosis was effected end to end with two layers of continuous catgut suture. This resection contained the greater number of intraluminal polyps. Two enterotomies were made, one some six feet from the duodeno-jejunal flexure and one about two feet from the ileo-caecal junction. A large pedunculated polyp was removed through each incision. No other large polyps were felt but during the performance of the anastomosis it was noted that both the duodenal and jejunal mucosa were finely polypoidal (Fig. 5). The wound was closed with stab drainage to the hepato-renal space.

\section{PATHOLOGY}

MACROSCOPIC APPEARANCE The specimens consisted of $80 \mathrm{~cm}$. of jejunum, $9 \mathrm{~cm}$. of duodenum, two polyps, and a small lymph node (Fig. 3). The jejunum contained eight pedunculated major polyps, the largest measuring $4 \mathrm{~cm}$. diameter. The mucosa throughout was covered by profuse sessile polyps varying in size from 1 to $4 \mathrm{~mm}$. (Figs. 4 and 5). The segment of duodenum presented a similar appearance but showed in addition a sessile polypoid area $1.5 \mathrm{~cm}$. diameter with some recent haemorrhage.

HISTOLOGY The polyps showed the typical structure seen in the Peutz-Jeghers syndrome. The stroma contained abundant smooth muscle with complex filiform branching in the larger lesions (Fig. 6). The epithelial element resembled fully differentiated small gut mucosa with villi, glands, and all cell types present in an essentially normal arrangement. Mitotic activity appeared normal. With the exception of the duodenal lesion none of the polyps sectioned showed evidence of malignancy. The major sessile polyp in the duodenum showed a similar structure but frank invasion by adenacarcinoma 
with mucoid areas was present in the base (Fig. 7). The origin of the carcinoma from the polyp epithelium could be seen with a well-defined transitional zone of atypical proliferation. The submucosa and muscle layers were invaded but the serosa was not involved.

The lymph node submitted was extensively invaded by similar tumour (Fig. 8).

\section{POST-OPERATIVE COURSE}

Post-operatively there was a prolonged ileus but eventually the patient made a good recovery. Subsequently sigmoidoscopy and barium enema examination showed the large bowel to be free of polyps.

The patient did well for a year but then began to complain of repeated vomiting without pain. A mass became evident in the right hypochondrium. Her condition steadily deteriorated and she died of cachexia 15 months after the operation. Permission for postmortem examination was not obtained.

\section{DISCUSSION}

The relationship of the Peutz-Jeghers syndrome to malignancy of the gastrointestinal tract has been the subject of considerable disagreement. Jeghers et al. (1949) considered that there was a definite risk of malignant change in polyps of the small gut although less marked than in the colonic polyps of familial polyposis coli. Aird (1952), Maingot (1955), and Berkowitz, Pearl, and Shapiro (1955) regarded the condition as pre-cancerous. Bailey (1957) expressed the view that the overall malignancy rate was about $24 \%$. In contrast, Dormandy (1957) in an admirable study of 81 cases, including 21 of his own, could find no acceptable case where the clinical course of the condition had supported a diagnosis of malignancy and no instance of lymphatic or distant metastasis. Staley and Schwartz (1957) also drew attention to the absence of metastasis and the discrepancy between the clinical course of the condition and the histological diagnosis of malignancy. The long survival of these patients is in sharp contrast to the known behaviour of true carcinoma of the small bowel, a tumour with a particularly poor prognosis.

There can be little doubt that the relatively numerous reports of malignant change in the Peutz-Jeghers syndrome are the result of misinterpretation of the unusual histological appearances. The structure of the Peutz-Jeghers polyp of the small bowel is quite characteristic and is well described by Dormandy (1957), Bartholomew, Dahlin, and Waugh (1957), and Rintala (1959). The stroma contains bands of smooth muscle which often exhibits complex branching. The epithelial element is of fully differentiated small bowel type with glands and villi. All cells in the normal mucosa are represented in essentially normal proportions. The complex structure of these polyps results in a deceptive appearance of stromal invasion when seen in sections. The polyps show the considerable mitotic activity normally present in small bowel mucosa and this also may contribute to an erroneous diagnosis of malignancy. The structure of these lesions has led Bartholomew et al. (1957) to suggest that they should be regarded as hamartomas, i.e., developmental abnormalities, rather than true neoplasms, a view later supported by Rintala (1959) and Morson (1960). This hypothesis may partly explain the rarity of malignant change in the Peutz-Jeghers syndrome but should not perhaps be taken too far, for the borderline between a hamartomatous malformation and a 'true tumour' is by no means distinct. Furthermore it must be remembered that quite apart from the occurrence of polyps primary carcinoma of the small gut is uncommon compared with its colonic counterpart, suggesting fundamental cellular or environmental differences.

Polyps may occur in this syndrome in both the stomach and large bowel but their frequency and nature is still somewhat uncertain. In most cases the colonic polyps have not been microscopically examined so that chance association with the common adenomatous polyps cannot be excluded. Relatively little information is available regarding the histology of the gastric and colonic lesions but in both situations polyps with branching smooth muscle bundles and an essentially hamartomatous structure have been described (Rintala, 1959; Bartholomew et al., 1957).

A few cases of cancer of the large bowel occurring with the Peutz-Jeghers syndrome are on record (Bailey, 1957) but in none is the pathological evidence sufficient to establish a relationship. Morson (1962) could find no example in the extensive records of St. Mark's Hospital collected over 30 years. The evidence at present available does not appear to justify the belief (Editorial, Lancet, 1961) that patients with this condition have a significantly increased incidence of rectal or colonic cancer.

Achord and Proctor (1963) report the death of a Negro girl aged 13 from gastric carcinoma associated with the Peutz-Jeghers syndrome and gastric polyps. The structure of the polyps, however, is not described and there is no clear indication that the tumour arose from a polyp. Nevertheless the age of this patient at least suggests a relationship. Horn, Payne, and Fine (1963) report fatal carcinoma, probably originating in the pylorus, in a Peutz-Jeghers patient aged 45 but the evidence in this case is inadequate to exclude coincidence. 
In conclusion it may be said that the PeutzJeghers syndrome carries very little risk of malignancy involving the small intestine; indeed we have been unable to find any other acceptable example in the literature. The relationship of the syndrome to carcinoma of the stomach and large bowel requires further study but the risk appears to be small. It must be emphasized that these are common sites for carcinoma and the strictest pathological criteria must be applied if chance association is to be excluded.

We wish to thank Mr. J. Scholefield for permission to publish this case and Mr. D. A. Vinten for the photographs.

\section{REFERENCES}

Achord, J. L., and Proctor, H. D. (1963). Malignant degeneration and metastasis in Peutz-Jeghers syndrome. Arch. intern. Med., 111, 498-502.

Aird, I. (1952). Intestines. In British Surgical Practice: Surgical Progress, 1952. Edited by E. R. Carling and J. P. Ross, pp. 171-187. Butterworth, London.

Bailey, D. (1957). Polyposis of gastrointestinal tract: the Peutz syndrome. Brit. med. J., 2, 433-439.
Bartholomew, L. G., Dahlin, D. C., and Waugh, J. M. (1957). Intestinal polyposis associated with mucocutaneous melanin pigmentation (Peutz-Jeghers syndrome). Gastroenterology, 32, 434-451.

Berkowitz, S. B., Pearl, M. J., and Shapiro, N. H. (1955). Syndrome of intestinal polyposis with melanosis of the lips and buccal mucosa: a study of the incidence and location of malignancy with three new case reports. Ann. Surg., 141, 129-133.

Dormandy, T. L. (1957). Gastrointestinal polyposis with mucocutaneous pigmentation (Peutz-Jeghers syndrome). New Engl. J. Med., 256, 1093-1103, 1141-1146, $1186-1190$.

Horn, R. C. Jr., Payne, W. A., and Fine, G. (1963). The PeutzJeghers syndrome (gastrointestinal polyposis with mucocutaneous pigmentation): report of a case terminating with disseminated gastrointestinal cancer. Arch. Path., 76, 29-37.

Jeghers, H., McKusick, V. A., and Katz, K. H. (1949). Generalized intestinal polyposis and melanin spots of the oral mucosa, lips and digits: a syndrome of diagnostic significance. New Engl. J. Med., 241, 993-1005, 1031-1036.

Lancet, (1961). (Editorial), Polyps et al., 1, 541-542.

Maingot, R. (1955). Abdominal Operations, 3rd ed. Appleton, New York.

Morson, B. C. (1960). Familial intestinal polyposis. Brit. med. J., 1, 1807.

- (1962). Precancerous lesions of upper gastrointestinal tract. J. Amer. med. Ass., 179, 311-315.

Peutz, J. L. A. (1921). A very remarkable case of familial polyposis of the mucous membrane of intestinal tract and nasopharynx accompanied by peculiar pigmentations of the skin and mucous membrane. [In Dutch.] Ned. Maandschr. Geneesk., 10, 134-146.

Rintala, A. (1959). The histological appearance of gastrointestinal polyps in the Peutz-Jeghers syndrome. Acta. chir. scand., 117, 366-373.

Staley, C. J., and Schwartz, H., II (1957). Gastrointestinal polyposi. and pigmentation of the oral mucosa (Peutz-Jeghers syndrome) Int. Abstr. Surg., 105, 1-15. 